\title{
Predictors of Nonunion in Humerus Shaft Fractures in Adults in Lomé (Togo)
}

\author{
Atchi Walla1*, Gamal Ayouba², Dadja Essoya Landoh ${ }^{3}$, Batarabadja Bakriga1, \\ Tchaa Towoezim¹, Anani Abalo1, Assang Michel Dossim¹ \\ ${ }^{1}$ Service de Chirurgie Orthopédique et Traumatologique, CHU Sylvanus Olympio, Lomé, Togo \\ ${ }^{2}$ Service de Chirurgie Générale du Centre Hospitalier de Kpalimé, Kpalimé, Togo \\ ${ }^{3}$ Division de l'Epidémiologie, Ministère de la Santé, Lomé, Togo \\ Email: *atchi.walla@yahoo.fr
}

Received 23 October 2015; accepted 17 November 2015; published 20 November 2015

Copyright (C) 2015 by authors and Scientific Research Publishing Inc.

This work is licensed under the Creative Commons Attribution International License (CC BY). http://creativecommons.org/licenses/by/4.0/

(c) (7) Open Access

\section{Abstract}

Background: To identify predictors of humerus shaft fractures nonunion in adults whatever the type of treatment performed. Patients and Methods: We conducted a retrospective study among patients who had a fracture of the humeral shaft moving towards healing or nonunion. Patients were treated in the orthopedic trauma unit of Sylvanus Olympio Teaching Hospital and two other private clinics in Lomé between January 2008 and June 2012. On the X-ray of each patient, we measured the angulation, the diastasis, and inter fragmentary contact. For each included patient, we looked for: age, sex, medical history, body mass index (BMI), according to the third location of the shaft fracture, the type of fracture according to AO classification and the type of opening according Tscherne classification. Results: During the study period, 184 patients with humeral shaft fracture were identified. Of these 108 were men. The mean age of patients was 37.3 years. The fractures were treated conservatively in 100 patients $(54.3 \%), 78$ treated surgically and six (3.3\%) have discharged from hospital against medical advice for traditional treatment. The factors that were associated with nonunion of humerus shaft fractures in these patients were: the opening of the fracture $(\mathrm{RR}=4.5 ; 95 \% \mathrm{CI}=[2.9 ; 7.1])$, the presence of immediately radial paralysis $(R R=5.6 ; 95 \% C I=[3.7 ; 8.5])$, the existence of other associated lesions or fracture $(R R=1.8 ; 95 \%$ $C I=[1.1 ; 3.1])$, energy of the trauma $(R R=2.3 ; 95 \% \mathrm{CI}=[1.3 ; 4.4])$ and type III classification of Tscherne (RR $=0.3 ; 95 \% \mathrm{CI}=[0.2 ; 0.6])$. After multivariate analysis, factors that remained significantly associated with the failure of consolidation were: the existence of diastasis $>2 \mathbf{m m}$ $(\mathrm{OR}=7.6 ; 95 \% \mathrm{CI}=[2.2 ; 25.6))$, the Body Mass Index $(\mathrm{BMI})>25(\mathrm{OR}=1.3 ; 95 \% \mathrm{CI}=[1.1-1.6])$ and the existence of other bone lesion $(\mathrm{OR}=4.3 ; 95 \% \mathrm{CI}=[1.4-18.9])$. Conclusion: $\mathrm{BMI}$ greater than 25 , the existence of an interfragmentary gap of more than $2 \mathrm{~mm}$ and existence of other bone lesions are significant risk factors for nonunion in humerus shaft fractures. The traditional treatment, common singular factor to the African environment, should not be ignored. Control of these predictors is necessary in carrying out the treatment of humerus shaft fractures.

\footnotetext{
${ }^{*}$ Corresponding author.
}

How to cite this paper: Walla, A., Ayouba, G., Landoh, D.E., Bakriga, B., Towoezim, T., Abalo, A. and Dossim, A.M. (2015) Predictors of Nonunion in Humerus Shaft Fractures in Adults in Lomé (Togo). Open Journal of Orthopedics, 5, 361-368. 


\section{Keywords}

\section{Humerus Shaft Fracture, Nonunion, Predisposing Factors}

\section{Introduction}

The frequency of the humeral fractures is between $5 \%$ and $8 \%$ of all fractures [1]. According to Mahmoud El-A Rosay, among humerus shaft fractures, treated conservatively, $2 \%-10 \%$ and around $15 \%$ treated surgically, progress to nonunion [2].

Nonunion is a debilitating complication for the patient [3], a challenge for the practitioner [1] and an economic burden to society [4]. Several factors have been cited as risk of nonunion in shaft fractures of the humerus including obesity, osteoporosis, alcoholism, smoking, poor bone quality and scar tissue [5]. Other publications still observed in many of these factors, technical errors [6] [7].

Because of rarity of African studies on this subject, we proposed to identify through our study, factors which, taken separately or combined could explain the occurrence of nonunion in African setting after treatment of humerus shaft fractures.

\section{Patients and Methods}

We conducted a retrospective study in patients with humeral shaft fractures moving towards healing or nonunion. The sample, consisting of 184 patients with shaft fractures, included the records of patients treated by the same team during the period from January 2008 to June 2012 in the orthopedic trauma unit of Sylvanus Olympio teaching hospital and two others privates clinics of Lomé. On each patient's humerus X-ray, we measured the following: angulation, the diastasis, and inter fragmentary contact after treatment. For each included participant, we looked for the age, sex, medical history, body mass index (BMI), the location of the fracture of the bone concerned, the type of fracture according to AO classification and the type of opening according to Tscherne classification. The study of body mass index was based on a simplified WHO classification and the International Obesity Task Force.

Conservative treatment consisted of the production of a thoracic outlet plaster or dangling plaster after or without reduction of the fracture. The implants used in cases of surgical treatment were plates, Seidel nail, and external fixators types of Hofmann second generation. Ten patients were operated on closed fracture.

Healing or nonunion of the fracture was observed on X-ray control six months after treatment.

Data were recorded using Epi Info software version 3.5.1. For continuous variables, means and standard deviation were calculated while for categorical variables we calculated proportions. Our primary outcome of interest was patient who developed nonunion fracture to ART compared to those who had their fracture consolidated. Pearson chi-square test or Fisher's exact test were used when appropriate in bivariate analysis.

In the multivariate logistic regression was performed to identify independent risk factors in the occurrence of nonunion fractures.

All the significant variables in the bivariate analysis with a p-value less than 0.05 and the previously known variables associated with the occurrence of nonunion were included in the multivariate analysis. However, we excluded from the model the variable "onset of paralysis" since there were missing values for a large number of subjects. We then removed from the model in a progressive manner the variables that were not significant with a p-value $>0.3$. No interaction was made in the logistic regression between variables included in the model.

\section{Ethical Aspects}

This study was authorized and conducted under the direction of the chief of orthopedic trauma unit of Sylvanus Olympio Teaching Hospital. This is a retrospective study consisting in the analysis of patient records; however, the privacy aspects were met: only aggregated data have been presented to ensure confidentiality.

\section{Results}

Of the 184 patients, 108 were male and 76 were female with a sex ratio $(\mathrm{M} / \mathrm{F})=1.4$. The mean age of the par- 
ticipant was 37.3 years ranging from 17 to 72 years old.

Seventy (70) patients (38.04\%) had a medical history of which $16 \%$ were alcoholics, $9 \%$ were tobacco users, $12 \%$ were diabetics, $18 \%$ had sickle cell disease.

\subsection{Lesional Characteristics}

There were 169 (91.8\%) cases of public highway accident, 7 cases (3.8\%) of work accident, 7 cases (3.8\%) of intentional injury and 1 case accident perfirearm.

In 22 patients (11.9\%), fractures were opened; 3 patients presented with major lesions of soft tissue. Bone lesions associated with humerus shaft fracture were recorded in 68 patients (36.9\%); 5 cases (2.7\%) were not documented. These bone lesions are detailed in Table 1.

There were 10 cases $(5.4 \%)$ of immediately radial paralysis.

Treatment was conservative in 100 patients (54.3\%) and surgical in 78 patients (42.4\%) while 6 patients (3.3\%) were discharged from hospital against medical advice for traditional treatment. The DCP plate was used in 89 patients, the Siedel nailin 5 patients and 3 patients with external fixators. Osteosynthesis were performed with autologousbone graft in 6 cases and without graft in86 cases. Radiological characteristics after the reduction are shown in Table 1.

\subsection{Outcome}

There was one (1) case of early postoperative superficial infection whose evolution was controlled. In total, 142 patients (77.2\%) consolidated after 6months of evolution and other patients (22.8\%) had progressed to nonunion fracture.

The factors that were associated with nonunion of humerus shaft fractures in these patients were: the opening of the fracture $(\mathrm{RR}=4.5 ; 95 \% \mathrm{CI}=[2.9 ; 7.1])$, the presence of radial paralysis immediately $(\mathrm{RR}=5.6 ; 95 \% \mathrm{CI}=[3.7$; 8.5]), the existence of other associated lesions or fracture $(\mathrm{RR}=1.8 ; 95 \% \mathrm{CI}=[1.1 ; 3.1])$, energy of the trauma $(\mathrm{RR}=2.3 ; 95 \% \mathrm{CI}=[1.3 ; 4.4])$ and type III classification of Tscherne $(\mathrm{RR}=0.3 ; 95 \% \mathrm{CI}=[0.2 ; 0.6])$. Patients with BMI between 25 and 28, and BMI greater than 28 were more likely to progress to nonunion than those with a BMI below 25 (Table 2).

In the multivariate analysis showed in Table 3 , factors that remained significantly associated with the failure of consolidation were: the existence of diastasis $>2 \mathrm{~mm}(\mathrm{OR}=7.6$; 95\% CI $=[2.2 ; 25.6)$ ), the Body Mass Index $(\mathrm{BMI})>25(\mathrm{OR}=1.3 ; 95 \% \mathrm{CI}=[1.1-1.6])$ and the existence of other bone lesion $(\mathrm{OR}=4.3 ; 95 \% \mathrm{CI}=[1.4-$ 18.9]).

\section{Discussion}

In this study, we found that three factors were significantly associated with the failure of consolidation of humerus shaft fractures were: the existence of diastasis $>2 \mathrm{~mm}$, the Body Mass Index (BMI) $>25$ and the existence of other bone lesion. In our study, female gender seems with $27.6 \%$ against $19.4 \%$ for men, tend to progress more to nonunion; however, the difference was not significant. This has been noted by BROADBENT [8] without providing an explanation on the real interference of the sex in the healing process.

Nonunion rate before 30 years old was $24 \%$; this rate decreased to $20.7 \%$ after 30 years. In the series of SOFCOT symposiumin 2004, there was a very marked nonunion rate in the age group of 15 - 35 years accounted for $49 \%$ of total nonunion [9]. This disparate distribution may mean that the age does not appear to be a factor in the occurrence of nonunional though osteoporosisis mentioned as a risk factor [10]; the difference between the results that can be attached to the sample used in our study. However it might be interesting to investigate the simultaneous influence of age and sex couple as postmenopausal women for example.

It appeared in various studies that obesity (BMI > 28) is a factor which can lead to the failure of consolidation [8] [10] [11]. In our study, obesity was significantly associated with the occurrence of nonunion. Obese patients with advanced toward nonunion, are predominantly female and treated conservatively (hanging humeral plaster or thoracic outlet plaster); fat masses and presence of breasts in these patients, can induce mobilities of fracture site that are harmful to the consolidation process.

The presence or absence of medical history in our study had no significant effect on the occurrence of nonunion; However, in our study sample, known factors of nonunion as, alcoholism, smoking, diabetes [10] [12] [13] have not all been documented because of the retrospective nature of the work. 
Table 1. Characteristics of the patients included in the study.

\begin{tabular}{|c|c|c|}
\hline & Cases number & Percentage (\%) \\
\hline \multicolumn{3}{|l|}{ Sex } \\
\hline Male & 108 & 59 \\
\hline Female & 76 & 41 \\
\hline \multicolumn{3}{|l|}{ Medical story } \\
\hline Yes & 70 & 38.04 \\
\hline No & 114 & 61.96 \\
\hline \multicolumn{3}{|l|}{ Type of accident } \\
\hline Work accident & 7 & 3.8 \\
\hline Highway accident & 169 & 91.8 \\
\hline Intentional injury & 7 & 3.8 \\
\hline Perfirearm & 1 & 0.6 \\
\hline \multicolumn{3}{|l|}{ Type of fracture } \\
\hline Open fractures & 22 & 12 \\
\hline Closed fractures & 162 & 88 \\
\hline \multicolumn{3}{|l|}{ Interfragmentary gap } \\
\hline$<2 \mathrm{~mm}$ & 77 & 41.8 \\
\hline Between 2 and $3 \mathrm{~mm}$ & 31 & 16.8 \\
\hline Between 3 and $4 \mathrm{~mm}$ & 4 & 2.2 \\
\hline$>4 \mathrm{~mm}$ & 0 & 0.0 \\
\hline Not documented & 72 & 39.1 \\
\hline \multicolumn{3}{|l|}{ Contact area } \\
\hline At least third circumference & 20 & 10.9 \\
\hline $1 / 3$ to $1 / 2$ circumference & 15 & 8.2 \\
\hline$>1 / 2$ circumference & 51 & 27.7 \\
\hline No contact & 4 & 2.2 \\
\hline Not documented & 94 & 51.1 \\
\hline \multicolumn{3}{|l|}{ Associated bone lesions } \\
\hline Yes & 68 & 37.9 \\
\hline No & 111 & 62.1 \\
\hline \multicolumn{3}{|l|}{ Type of bone associated lesions } \\
\hline Femur fracture & 4 & 5.9 \\
\hline Tibia fracture & 8 & 11.8 \\
\hline Femur and tibia fractures & 7 & 10.3 \\
\hline Tibia and distal humerus fractures & 3 & 4.4 \\
\hline Tibia and forearm fractures & 4 & 5.9 \\
\hline Distal humeral fracture & 6 & 8.8 \\
\hline Wrist fracture & 3 & 4.4 \\
\hline Ribs fractures & 7 & 10.3 \\
\hline Forearm and ribs fractures & 3 & 4.4 \\
\hline Fracture of hand and foot squelet & 23 & 33.8 \\
\hline
\end{tabular}


Table 2. Factors associated with nonunion.

\begin{tabular}{|c|c|c|c|c|c|}
\hline & Nonunion N (\%) & Consolidation N (\%) & RR & $95 \%$ CI & $\mathrm{p}$ \\
\hline \multicolumn{6}{|l|}{ Sex } \\
\hline Female & $21(27.6)$ & $55(72.4)$ & & & \multirow{2}{*}{0.19} \\
\hline Male & $21(19.4)$ & 87 (80.6) & 1.4 & $0.8-2.4$ & \\
\hline \multicolumn{6}{|l|}{ Age } \\
\hline$<30$ ans & $24(24.7)$ & $73(75.3)$ & & & \\
\hline$>30$ ans & $18(20.7)$ & $69(79.3)$ & 1.2 & $0.7-2.1$ & 0.6 \\
\hline \multicolumn{6}{|l|}{ BMI } \\
\hline$<25$ & $16(14.5)$ & $94(85.5)$ & Ref & & \\
\hline [25 - 28] & $13(29.5)$ & $31(70.5)$ & 2.1 & $1.1-3.9$ & 0.05 \\
\hline$>28$ & $9(47.4)$ & $10(52.6)$ & 3.3 & $1.7-6.3$ & 0.002 \\
\hline \multicolumn{6}{|l|}{ Medical story } \\
\hline Yes & $14(20)$ & $56(80)$ & & & \multirow{2}{*}{0.59} \\
\hline No & $28(24.6)$ & $86(75.4)$ & 1.2 & $0.7-2.2$ & \\
\hline \multicolumn{6}{|l|}{ Type of fracture } \\
\hline Open & $16(72.7)$ & $6(27.3)$ & & & \multirow{2}{*}{$<0.001$} \\
\hline Closed & $26(16.1)$ & $136(83.9)$ & 4.5 & $2.9-7.1$ & \\
\hline \multicolumn{6}{|c|}{ Immediately radial paralysis } \\
\hline Yes & 9 & 1 & & & \multirow{2}{*}{$<0.001$} \\
\hline No & 24 & 125 & 5.6 & $3.7-8.5$ & \\
\hline \multicolumn{6}{|l|}{ Associated bone lesions } \\
\hline Yes & 22 & 46 & & & \multirow{2}{*}{0.04} \\
\hline No & 20 & 91 & 1.8 & $1.1-3.1$ & \\
\hline \multicolumn{6}{|l|}{ Traumaenergy } \\
\hline Low & 15 (31.9) & $32(68.1)$ & Ref & & \\
\hline Average & 15 (13.6) & $95(86.4)$ & 2.3 & $1.3-4.4$ & 0.007 \\
\hline Strong & $12(44.4)$ & $15(56.6)$ & 0.7 & $0.4-1.3$ & 0.4 \\
\hline \multicolumn{6}{|l|}{ Stroke type } \\
\hline Single transverse & $16(20.0)$ & $64(80.0)$ & Ref & & \\
\hline Long or short oblique & $2(18.2)$ & $9(81.8)$ & 1.1 & $0.3-4.2$ & 0.6 \\
\hline Comminuted & $8(21.1)$ & 30 (78.9) & 0.9 & $0.5-2.1$ & 0.9 \\
\hline With third fragment & $16(29.1)$ & 39 (70.9) & 0.7 & $0.4-1.3$ & 0.3 \\
\hline \multicolumn{6}{|l|}{ Tscherne classification } \\
\hline Tscherne 1 & $14(21.9)$ & $50(78.1)$ & & & \\
\hline Tscherne 2 & $15(15.8)$ & $80(84.2)$ & 1.4 & $0.7-2.7$ & 0.4 \\
\hline Tscherne 3 & $13(65.0)$ & $7(35.0)$ & 0.3 & $0.2-0.6$ & $<0.001$ \\
\hline
\end{tabular}


Continued

\begin{tabular}{|c|c|c|c|c|c|}
\hline Fracture sit & & & & & \\
\hline Upper $1 / 3$ & $12(20.0)$ & 48 (81.4) & & & \\
\hline Midle 1/3 & $25(24.0)$ & $79(76.0)$ & 0.8 & $0.5-1.5$ & 0.7 \\
\hline Less 1/3 Inférieur & $5(25.0)$ & $15(75.0)$ & 0.8 & $0.3-1.9$ & 0.8 \\
\hline \multicolumn{6}{|l|}{ Type of treatment } \\
\hline Conservative & $29(34.5)$ & 55 (65.5) & & & \multirow{2}{*}{$<0.001$} \\
\hline Surgical & $13(13.0)$ & $87(87.0)$ & 2.7 & $1.5-4.8$ & \\
\hline \multicolumn{6}{|c|}{$\begin{array}{l}\text { Lack of immobilization } \\
\text { (traditional treatment) }\end{array}$} \\
\hline Yes & $6(100)$ & $0(0)$ & & & \multirow{2}{*}{$<0.001$} \\
\hline No & $36(20.2)$ & $142(79.8)$ & 4.9 & $3.7-6.6$ & \\
\hline \multicolumn{6}{|l|}{ Interfragmentary gap } \\
\hline$>2 \mathrm{~mm}$ & $17(48.6)$ & 18 (51.4) & & & \multirow{2}{*}{$<0.001$} \\
\hline$<2 \mathrm{~mm}$ & $8(10.4)$ & $69(89.6)$ & 4.7 & $2.2-9.8$ & \\
\hline
\end{tabular}

Table 3. Multivariate analysis of possible factors of nonunion.

\begin{tabular}{|c|c|c|c|c|}
\hline & Odds ratio & $95 \% \mathrm{CI}$ & Coefficient & p-value \\
\hline Interfragmentary gap > $2 \mathrm{~mm}$ & 7.6 & $2.2-25.6$ & 2 & $0.0011^{*}$ \\
\hline BMI & 1.3 & $1.1-1.6$ & -0.3 & $0.0376^{*}$ \\
\hline Bone associated lesions & 5.3 & $1.4-18.9$ & 1.7 & $0.011^{*}$ \\
\hline Conservative treatment & 2.4 & $0.6-10.2$ & 0.9 & 0.2349 \\
\hline Energy of trauma & 0.5 & $0.0-90.9$ & -0.6 & 0.8071 \\
\hline
\end{tabular}

\subsection{Lesional Factors}

The opening of the fracture with the spoliation of consolidation factors and the involvement of a high-energy trauma that generates soft tissue lesions are factors identified by several authors as being able significantly determine the evolution of a fracture to the failure of consolidation [14] [15].

The radial paralysis at the outset was a factor significantly associated with nonunion in study. The role of the nervous system in bone metabolism has been demonstrated by HURRELL [16] which found that the growth and bone remodeling were affected through osteoblasts in connection with the nerve fibers; studies of FRYMOYER [17] and MADSEN [18] reported that the resection of the sciatic nerve induced a mechanically insufficient callus after fracture in rats. CHERRUAU discovered that nerve damage can affect bone metabolism due to the release of neuropeptides [19]; also, TOGARI [20] reveals the possible involvement of the nerve dysfunction, which may inhibit bone formation and accelerated bone resorption by reducing releases of neuromodulators factors [21]. It is therefore apparent that the radial palsy outset could play a role in the evolution of the humerus fracture to nonunion; however, larger series will allow better study this factor.

The type of stroke and the seat of the fracture were not significantly associated with nonunion factors in our study as in the work of MARTINEZ [22]; results published on this subject vary widely. While DECOMAS [23], RING [24], and VOLGAS have criminalized short oblique fracture line, others like BABA [25] found that the open comminuted fracture in the middle third was directly associated with nonunion.

Others found instead that the transverse feature was predictive factor of nonunion [8] [10]. These different results may want to indicate that the anatomical type of fracture in itself does not interfere directly in the occurrence of nonunion but its association with the gap inter fragmentary than $3 \mathrm{~mm}$ and the interposition of soft tissues could determine nonunion [7] [26]. However, the height of the gap selected for our study was $2 \mathrm{~mm}$. 


\subsection{Therapeutic Factors}

The orthopedic treatment and diastasis greater than 3mmare recognized aspotential factors for developing nonunion [7] [9]; its occurrence if surgical treatment is related to technical errors during osteosynthesis [7] [27].

In sufficientor in adequate immobilization can lead to nonunion [8] [10]. This data was found in our study with positive association of traditional treatment and nonunion; in our sample, all patients who have opted for the traditional treatment for lack of financial means, returnedtous for nonunion; this factor remains a feature of developing countries like ours with very low incomes, do not allow everyone access to conventional care; these poor patients then turn to the healer in which the asset is illusory and broken homes subjected to unwanted massages are mobileas demonstrated OGUNLADE [26].

Smoking, work accident and standard interfragmentary than $3 \mathrm{~mm}$ were, in analyzing the series of SOFCOT, statistically significant factors in multivariate analysis [9].

This difference may be related to this type of retrospective study that was not allowing an exhaustive study of the factors that negatively influence bone healing; in addition, this ample size was limited in Lomé. An extensive prospective study taking in account the rest of the country would be more objective.

\section{Conclusion}

BMI greater than 25 and the existence of interfragmentary gap of more than $2 \mathrm{~mm}$ and bone lesions are significant risk factors for nonunion in the multivariate analysis. In the bivariate analysis, the traditional treatment remains a singular risk factor, specific to developing countries such as ours. It should not be ignored. Control of these predictors is necessary in carrying out the treatment of humerus shaft fractures to prevent nonunion.

\section{References}

[1] Volgas, D.A., Stannard, J.P. and Alonso, J.E. (2004) Nonunions of the Humerus. Clinical Orthopaedics and Related Research, 419, 46-50. http://dx.doi.org/10.1097/00003086-200402000-00008

[2] El-Rosasy, M.A. (2012) Nonunited Humerus Shaft Fractures Treated by External Fixator. Indian Journal of Orthopaedics, 46, 58-64. http://dx.doi.org/10.4103/0019-5413.91636

[3] Hierholzer, C., Sama, D., Toro, J.B., Peterson, M. and Helfet, D.L. (2006) Plate Fixation of Ununited Humeral Shaft Fractures: Effect of Type of Bone Graft on Healing. Journal of Bone \& Joint Surgery (American Volume), 88, 14421447. http://dx.doi.org/10.2106/JBJS.E.00332

[4] Flierl, M.A., Smith, W.R., Mauffrey, C., Irgit, K., Williams, A.E., Ross, E., Peacher, G., Hak, D.J. and Stahel, P.F. (2013) Outcomes and Complication Rates of Different Bone Grafting Modalities in Long Bone Fracture Nonunions: A Retrospective Cohort Study in 182 Patients. Journal of Orthopaedic Surgery and Research, 8, 33. http://dx.doi.org/10.1186/1749-799X-8-33

[5] King, A.R., Moran, S.L. and Steinmann, S.P. (2007) Humeral Nonunion. Hand Clinics, 23, 449-456. http://dx.doi.org/10.1016/j.hcl.2007.09.003

[6] Baba, R. and Razak, M. (1998) Contributing Factors in Non-Union of the Humeral Shaft Fracture and the Results of Treatments. Medical Journal of Malaysia, 53, 42-51.

[7] Zehi, K., Mnif, H., Saadaoui, F., Ben Amor, H., Litaiem, T. and Douik, M. (2002) Les pseudarthroses post-traumatiques de l'humérus: A propos d'une série de 60 cas. Revue de Chirurgie Orthopédique, 88, 234.

[8] Broadbent, M.R., Will, E. and McQueen, M.M. (2010) Prediction of Outcome after Humeral Diaphyseal Fracture. Injury, 41, 572-577. http://dx.doi.org/10.1016/j.injury.2009.09.023

[9] Passuti, N., Waast, D., Piétu, G. and Gouin, F. (2004) Fractures diaphysaires de l'humérus chez l'adulte. Revue de Chirurgie Orthopédique Supplement, 90, 57-60.

[10] Abalo, A., Dosseh, E.D., Adabra, K., Walla, A., James, Y.E. and Dossim, A. (2011) Open Reduction and Internal Fixation of Humeral Non-Unions: Radiological and Functional Results. Acta Orthopaedica Belgica, 77, 299-303.

[11] Foulk, D.A. and Szabo, R.M. (1995) Diaphyseal Humerus Fractures: Natural History and Occurrence of Nonunion. Orthopedics, 18, 333-335.

[12] Volgas, D.A., Stannard, J.P. and Alonso, J.E. (2004) Nonunions of the Humerus. Clinical Orthopaedics and Related Research, 419, 46-50. http://dx.doi.org/10.1097/00003086-200402000-00008

[13] Hernandez, R.K., Do, T.P., Critchlow, C.W., Dent, R.E. and Jick, S.S. (2012) Patient-Related Risk Factors for Fracture-Healing Complications in the United Kingdom General Practice Research Database. Acta Orthopaedica, 83, 653-660. http://dx.doi.org/10.3109/17453674.2012.747054 
[14] Chua, W., Murphy, D., Siow, W., Kagda, F. and Thambiah, J. (2012) Epidemiological Analysis of Outcomes in 323 Open Tibial Diaphyseal Fractures: A Nine-Year Experience. Singapore Medical Journal, 53, 385-389.

[15] Masquelet, A.C. (2004) Chirurgie orthopédique, principes et généralités. Masson, Paris, 363-368.

[16] Hurrell, D.J. (1937) The Nerve Supply of Bone. Journal of Anatomy, 72, 54-61.

[17] Frymoyer, J.W. and Pope, M.H. (1977) Fracture Healing in the Sciatically Denervated Rat. The Journal of Trauma, 17, 355-361. http://dx.doi.org/10.1097/00005373-197705000-00004

[18] Madsen, J.E., Hukkanen, M., Aune, A.K., Basran, I., Moller, J.F., Polak, J.M. and Nordsletten, L. (1998) Fracture Healing and Callus Innervation after Peripheral Nerve Resection in Rats. Clinical Orthopaedics and Related Research, 351, 230-240. http://dx.doi.org/10.1097/00003086-199806000-00028

[19] Cherruau, M., Morvan, F.O., Schirar, A. and Saffar, J.L. (2003) Chemical Sympathectomy-Induced Changes in TH-, VIP-, and CGRP-Immunoreactive Fibers in the Rat Mandible Periosteum: Influence on Bone Resorption. Journal of Cellular Physiology, 194, 341-348. http://dx.doi.org/10.1002/jcp.10209

[20] Togari, A. (2002) Adrenergic Regulation of Bone Metabolism: Possible Involvement of Sympathetic Innervation of Osteoblastic and Osteoclastic Cells. Microscopy Research and Technique, 58, 77-84. http://dx.doi.org/10.1002/jemt.10121

[21] Song, D.H., Jiang, X.W., Zhu, S.S., Li, W.Y., Khadka, A. and Hu, J. (2012) Denervation Impairs Bone Regeneration during Distraction Osteogenesis in Rabbit Tibia Lengthening. Acta Orthopaedica, 83, 406-410. http://dx.doi.org/10.3109/17453674.2012.702389

[22] Martinez, A.A.M., Herrera, A.R. and Cuenca Espierrez, J. (2003) Facteurs prédictifs de la pseudarthrose de l'humérus dans les fractures fermées diaphysaires. Revista de Ortopedia y Traumatología, 47, 31-37.

[23] Decomas, A. and Kaye, J. (2010) Risk Factors Associated with Failure of Treatment of Humeral Diaphyseal Fractures after Functional Bracing. Journal of the Louisiana State Medical Society, 162, 33-35.

[24] Ring, D., Chin, K., Taghinia, A. and Jupiter, J.B. (2007) Non-Union after Functional Brace Treatment of Diaphyseal Humerus Fractures. The Journal of Trauma, 62, 1157-1158. http://dx.doi.org/10.1097/01.ta.0000222719.52619.2c

[25] Baba, R. and Razak, M. (1998) Contributing Factors in Non-Union of the Humeral Shaft Fracture and the Results of Treatments. Medical Journal of Malaysia, 53, 42-51.

[26] Ogunlade, S.O., Omololu, A.B., Alonge, T.O., Diete, S.T. and Obawonyi, J.E. (2011) Predisposing Factors and Outcome of Treatment of Non-Union of Long-Bone Fractures in Ibadan, Nigeria. The Nigerian Postgraduate Medical Journal, 18, 56-60.

[27] Dujardin, F.-H., Mazirt, N. and Tobenas, A.-C. (2000) Echec de l'enclouage centro-médullaire verrouillé des pseudarthroses de la diaphyse humérale. Revue de chirurgie orthopédique et réparatrice de l'appareil moteur, 86, $773-$ 780 . 